\title{
Índice de Mobilidade Urbana Sustentável (IMUS) para o Domínio Planejamento Integrado em Sinop-MT
}

\section{Sustainable Urban Mobility Index (IMUS) for the Planning Field Integrated in Sinop-MT}

\author{
${ }^{1}$ Paulo Ferreira, ${ }^{2}$ Emeli Lalesca Aparecida da Guarda, ${ }^{3}$ Marlon Leão, ${ }^{4}$ João Carlos Machado Sanches, \\ ${ }^{5}$ Luís Shigeharu Ohira
}

\begin{abstract}
${ }^{1}$ Engenheiro Civil, Faculdade de Ciências Exatas e Tecnológicas, FACET, Graduado na Universidade de Mato Grosso, Av. dos Ingás, 3001, Sinop-MT(gympel@ufmt.br)

${ }^{2}$ Mestranda do Programa de Pós-graduação em Engenharia de Edificações e Ambiental da Faculdade de Arquitetura, PPGEEA, Universidade Federal de Mato Grosso, Av. Fernando Correa da Costa, 2367, FAET,

Cuiabá-MT, (emeliguarda@gmail.com) ${ }^{3}$ Doutor em Engenharia Civil na área de Eficiência Energética, Faculdade de Ciências Exatas e Tecnológicas, FACET, Universidade de Mato Grosso, Av. dos Ingás, 3001, Sinop-MT, (leao@ unemat.br) ${ }^{4}$ Doutor em Urbanismo, Faculdade de Ciências Exatas e Tecnológicas, FACET, Universidade de Mato Grosso, Av. dos Ingás, 3001, Sinop-MT, (sanches@unemat-net.br) ${ }^{5}$ Mestre em Ciências Ambientais, Faculdade de Ciências Exatas e Tecnológicas, FACET, Graduado na Universidade de Mato Grosso, Av. dos Ingás, 3001, Sinop-MT.
\end{abstract}

RESUMO: Com base no Índice de Mobilidade Urbana Sustentável - IMUS- desenvolvido por Costa (2008) este trabalho tem por objetivo aferir, por meio do cálculo dos indicadores, os aspectos positivos e negativos na atual conjuntura de desenvolvimento e mobilidade urbana, relacionado ao domínio Planejamento Integrado, no município de Sinop/MT. Os dados aferidos entre os meses de agosto e outubro de 2015 estão relacionados a um contexto específico no tempo, podendo ser reavaliados em situações futuras, em função de mudanças de ordem econômica, social, ambiental ou do próprio sistema de mobilidade urbana. Obteve-se o IMUS de 0,551 para o município de Sinop. Nesta avaliação, considera-se que Sinop atingiu uma pontuação mediana de acordo com a escala proposta pelo IMUS. O município tem buscado a viabilização de um desenvolvimento mais sustentável, porém, ainda tem muito que ajustar quanto ao planejamento integrado, a partir de ações integradas e de pessoal qualificado. As ações de reconhecimento e fiscalização estão presentes, ainda assim, o município possui pendências de regularização de novos bairros e condomínios residenciais, faltam escolas e postos de saúde, reflexos do constante e acentuado crescimento do município. Observa-se ainda que os problemas encontrados impactam de maneira mais significativas as populações mais carentes, que ocupam as áreas mais distantes do centro da cidade.

Palavras Chave: Mobilidade urbana. Planejamento integrado. Sustentabilidade.

ABSTRACT: Based on the Sustainable Urban Mobility Index (IMUS) developed by Costa (2008), this study aims to assess, through the calculation of the indicators, the positive and negative aspects of the current urban development and mobility scenario, related to the Integrated Planning domain, in the municipality of Sinop / MT. The data obtained between August and October 2015 are related to a specific context in time, and can be reassessed in future situations, due to changes in economic, social, environmental or the urban mobility system itself. The IMUS of 0.551 was obtained for the municipality of Sinop. In this evaluation, Sinop is considered to have reached a median score according to the scale proposed by IMUS. The municipality has sought the viability of a more sustainable development, however, it still has much to adjust regarding integrated planning, based on integrated actions and qualified personnel. Recognition and inspection actions are present, yet the municipality has pending regularization of new neighborhoods and residential condominiums, schools and health posts are missing, reflecting the constant and strong growth of the municipality. It is also noted that the problems encountered impact the most deprived populations, which occupy the most distant areas of the city center.

Keywords: Urban mobility. Integrated planning. Sustainability.

\section{INTRODUÇÃO}

De acordo com Costa (2008) entre os anos de 1960 e 1980, época do Regime Militar no Brasil, as principais cidades do país tiveram crescimento acentuado. E, não havendo diretrizes nacionais para sistematizar este crescimento de forma ordenada, cada município construiu sua história. Assim, as cidades se transformaram em aglomerações urbanas com muitos problemas de mobilidade. 
Neste sentido, Pereira e Rezende (2013) acentuam que a partir da Constituição de 1988 passou-se a exigir dos governantes, opções de serviços com qualidade. Com isso, as ações governistas passaram a ser mais controladas, a fim de orientar a melhor utilização dos recursos disponíveis, exigindo ações governamentais cada vez mais efetivas. Desta forma, vários instrumentos para este controle foram importantes neste processo, como a Lei de Responsabilidade Fiscal (LRF) que estabeleceu normas de finanças públicas voltadas para a responsabilidade na gestão fiscal da União, dos Estados, do Distrito Federal e dos Municípios. Portanto, obedecer a estes critérios é essencial aos municípios, uma vez que, a execução das ações governamentais está condicionada ao previsto no Plano Plurianual (PPA), na Lei de Diretrizes Orçamentárias (LDO) e na Lei Orçamentária Anual (LOA).

Para Carmo e Garcia Neto (2010) a base legal na gestão municipal está ligada ao Plano Diretor e à Lei Orgânica Municipal, que regem os interesses econômicos, políticos e sociais de um município, sendo o Plano Diretor o documento que regulamenta essas leis da cidade. Ressalta-se neste contexto, que o Plano Diretor é uma obrigatoriedade para os municípios com mais de vinte mil habitantes desde a Constituição de 1988. Costa (2008) complementa que embora a Constituição Federal tenha sido importante para este debate, é no Estatuto das Cidades (Lei Federal no 10.257 de 2001) que regulamenta os artigos 182 e 183 da Constituição Federal e da criação do Ministério das Cidades em 2003, que a integração entre planejamento urbano e transporte começou a ser discutida de forma mais ampla no Brasil.

O Plano Diretor de Desenvolvimento Integrado (SINOP, 2006) estabelece as diretrizes da Política Municipal de Mobilidade Urbana, considerando como infraestrutura de mobilidade urbana: calçadas, passarelas, passagens, faixas de pedestres, ciclovias, ciclofaixas e outros itens. Os objetivos do Plano Diretor de Sinop voltados para o desenvolvimento do modo de transportes não motorizados, entre outros, são: garantir a apropriação do uso do espaço urbano por pedestres e ciclistas; expandir, promover e melhorar o uso dos transportes não motorizados no município; priorizar pedestres, ciclistas, passageiros de transporte coletivo, pessoas com necessidades especiais e idosos; promover e apoiar a implementação de sistemas cicloviários seguros, em especial aqueles integrados à rede de transporte público; e incentivar a utilização da bicicleta como meio de transporte e sua utilização como lazer (Sinop, 2006).

Colaborando com essa discussão, Costa (2008) desenvolve o Índice de Mobilidade Urbana Sustentável - IMUS, composto por nove domínios, sendo: (i) acessibilidade, (ii) aspectos ambientais, (iii) aspectos sociais, (iv) aspectos políticos, (v) infraestrutura de transportes, (vi) modos não motorizados, (vii) planejamento integrado, (viii) tráfego e circulação urbana e (ix) sistemas de transporte urbano. Esses domínios foram definidos através da discussão com profissionais ligados à área de mobilidade urbana em workshops realizados em onze cidades brasileiras, espalhadas por todas as regiões do país. Dessa forma, os domínios refletem os assuntos comuns que são capazes de caracterizar a mobilidade urbana dos municípios brasileiros de médio porte.

Neste contexto, o objetivo desta pesquisa é avaliar o sistema de mobilidade urbana para o município de Sinop/MT, para o domínio do planejamento integrado. Busca-se contribuir com análises e ações que colaborem para uma gestão estratégica, eficaz e sustentável da mobilidade, com destaque para o atendimento às populações mais carentes. Insere-se ainda na discussão da revisão do Plano Diretor Municipal, que completou 10 anos de aplicação no ano de 2016. 


\section{FUNDAMENTAÇÃO TEÓRICA}

\section{1 Índice de Mobilidade Urbana Sustentável - IMUS}

As questões urbanas se apresentam de forma complexa, havendo diversos aspectos a serem levados em consideração nos processos de planejamento, ainda mais quando há enfoque nas questões relacionadas à sustentabilidade.

Desta forma, torna-se importante o uso de ferramentas que possam aferir indicadores que orientem as ações dos gestores e de projetos para o desenvolvimento urbano sustentável, e que considere e avalie os aspectos sociais, ambientais, físicos e econômicos. Contudo, para que isso aconteça, são necessárias novas formas de atuação nos processos de planejamento.

O IMUS, desenvolvido por Costa (2008), visa avaliar a sustentabilidade da mobilidade nas cidades brasileiras. Trata-se de uma ferramenta que observa as características regionais para que possa ser utilizada em todo o país. Mancini (2011) ressalta que, por envolver aspectos como política, sociedade, economia, meio ambiente e urbanismo, o IMUS é uma importante ferramenta de avaliação de uma cidade, permite mensurar e delimitar o contexto vigente nas cidades em que é aplicado.

\subsection{Aplicação do IMUS em municípios brasileiros}

O IMUS já foi aplicado como ferramenta de avaliação da mobilidade urbana por diversos pesquisadores em algumas cidades brasileiras, como: São Carlos-SP por Costa (2008), Brasília-DF por Pontes (2010), Curitiba-PR por Miranda (2010), Anápolis-GO por Morais (2012), Uberlândia-MG por Assunção (2012), Fortaleza-CE por Maia (2013), Goiânia-GO por Abdala (2013) e Natal-RN por Costa (2014).

Após a elaboração da tese de Costa (2008) em São Carlos, com o desenvolvimento e aplicação geral do índice, outros trabalhos foram feitos com o objetivo de calculá-lo, em outros municípios. Os trabalhos aqui consultados são dos municípios: Goiânia-GO, de Abdala (2013), Uberlândia-MG, de Assunção (2012), Curitiba-PR, de Miranda (2010), Anápolis-GO, de Morais (2012) e Brasília-DF, de Pontes (2010).

De acordo com Costa (2008), a existência de estudos envolvendo o cálculo do IMUS em diferentes municípios é importante para a revisão dos métodos de cálculo dos indicadores, com base nas adaptações a serem feitas para adequá-los na base de dados. É importante também para servir de parâmetro para a atualização do índice em casos necessários, uma vez que as mudanças ocorridas em torno da mobilidade urbana podem alterar a influência de certos aspectos assim como pode colaborar para uma estabilidade. Além disso, o IMUS pode ser utilizado como uma ferramenta comparativa entre os diferentes municípios, apontando locais que são referência, de modo positivo ou negativo.

\section{MATERIAIS E MÉTODOS}

Os dados utilizados estão relacionados à um período específico de tempo, neste caso abrangendo os anos de 2014 e 2015, podendo ser reavaliados em situações futuras, em função de mudanças, sejam elas de ordem econômica, social, ambiental ou do próprio sistema de mobilidade urbana.

A metodologia tem por procedimento basilar o Guia de Indicadores em anexo à tese de Costa (2008), em que se obtêm as definições, os dados base, as fontes de dados, métodos de pesquisa, bem como as formas de cálculo e avaliação para cada indicador.

Desta forma, os domínios, temas e indicadores recebem um peso associado e são utilizados na definição da pontuação do domínio, tema e indicador. O IMUS ainda permite a avaliação dos domínios mesmo que alguns indicadores sejam retirados, que pode ocorrer quando não é possível o levantamento dos dados necessários (score vazio). Neste caso, o seu 
FERREIRA, PAULO; et al; Índice de Mobilidade Urbana Sustentável (IMUS) para o Domínio Planejamento Integrado em Sinop-MT. E\&S Engineering and Science, (2018), 7:2.

peso deve ser redistribuído de forma que a somatória dos pesos dos indicadores de determinado tema seja igual a 1,00 .

No caso do domínio Planejamento Integrado, os temas e indicadores foram construídos de acordo com o esquema apresentado na Figura 1.

Figura 1 - Indicadores do planejamento integrado - IMUS

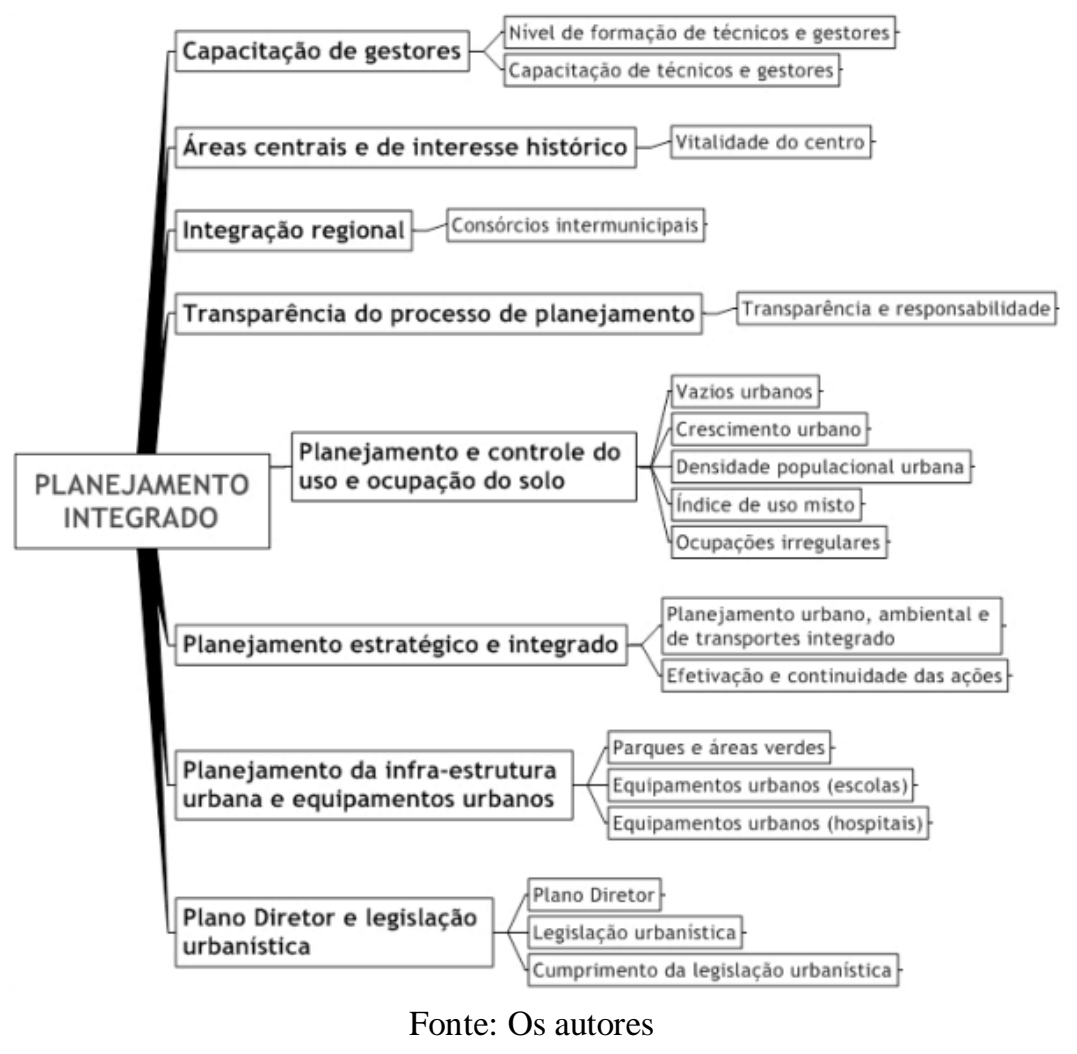

O IMUS adota um modelo de agregação dos critérios que permite sua compensação, ou seja, permite que um critério de qualidade baixa seja compensado por um conjunto de critérios de maior qualidade. Assim, constitui uma ferramenta de fácil compreensão e simplicidade de aplicação, não exigindo pacotes computacionais específicos, nem conhecimento de modelos matemáticos complexos para sua utilização (Costa et. al., 2007).

As ferramentas específicas, fontes e critérios utilizados para a identificação dos diferentes temas e indicadores serão descritos nos subitens subsequentes.

\subsection{Domínios: Planejamento Integrado}

3.1.1 Tema: Capacitações de gestores

a) Nível de formação de técnicos e gestores

O levantamento deste indicador foi feito junto ao Núcleo de Projetos e Desenvolvimento Urbano de Sinop (PRODEURBS) e Secretaria de Trânsito e Transporte Urbano (STU), que forneceram, através de documentos, o quadro de funcionários atualizado. De posse desses dados, verificou-se a porcentagens de técnicos e gestores de órgãos de planejamento urbano, transportes e mobilidade, no ano de referência, que possuem qualificação superior. Para este indicador, os valores de referência, descritos em Costa (2008) variam de até 5\% (score 0,00) a $25 \%$ ou mais (score 1,00 ).

\section{B) Capacitação de técnicos e gestores}

Os dados para este indicador foram coletados junto à secretaria de governo por meio de entrevista com o funcionário do setor, coordenador da Escola de Governo, à época da entrevista. 
Segundo ele, foram fornecidas palestras, treinamentos e cursos para os técnicos e gestores das secretarias, e os certificados estão registrados no livro de registro da Escola de Governo. Dessa forma, o score é avaliado de acordo com horas/funcionários/ano de cursos e treinamentos oferecidos a técnicos e gestores das áreas de planejamento urbano, transportes e mobilidade no ano de referência. Os valores de referência variam de 8 horas ou menos (score 0,00$)$ a 40 horas ou mais (score 1,00).

\subsubsection{Tema: Áreas centrais de interesse histórico}

a) Vitalidade do centro

Os dados obtidos para esse indicador foram retirados do site RAIS CAGED, do IBGE para o município de Sinop, e da observação do mapa de uso solo urbano fornecido por Sanches (2015). A partir de um software de desenho assistido por computador, foi possível chegar ao número de empregos para o comércio e ao número de domicílios da área central para o ano base (2010) e para o ano de referência (2014). Após esses resultados, utilizou-se a equação a baixo para obter o valor do score.

$$
I=\left(\frac{D}{D o}+\frac{E}{E o}\right)
$$

sendo:

$\mathrm{I}=$ Medida da vitalidade da área central;

$\mathrm{D}=$ Números de domicílios na área central da cidade no ano de referência;

$\mathrm{D}_{0}=$ Números de domicílios na área central da cidade para o ano base;

$\mathrm{E}=$ Números de empregos nos segmentos do comércio na área central da cidade para o ano de referência; e,

$\mathrm{E}_{0}=$ Números de empregos nos segmentos de comércio na área central da cidade para o ano base.

Portanto para a avaliação do score verifica-se o valor de "I", variando de I $<0,50$, quando o centro apresenta forte tendência de esvaziamento com declínio acentuado do número de domicílios particulares e empregos nos setores de comércio e serviços, e forte desequilíbrio entre as atividades diurnas e noturnas, até I $>1,50$, quando o centro apresenta forte tendência de crescimento do número de domicílios particulares e empregos, nos setores de comércio e serviços, e forte equilíbrio entre as atividades diurnas e noturnas.

\subsubsection{Tema: Integração Regional}

\section{a) Consórcios intermunicipais}

Os dados para este indicador foram levantados junto às Secretarias de Orçamento e de Contabilidade do município e repassados apenas verbalmente por funcionários adjuntos à secretaria, nos meses de novembro e dezembro de 2014. De posse desses dados, analisou-se o score de acordo com os valores de referência estabelecidos, variando das constatações de que não foram firmados ou encontra-se em vigor nenhum consórcio intermunicipal para provisão de infraestrutura e prestação de serviços (score 0,00) até aquisições de máquinas e equipamentos, execução de obras de manutenção e construção de infraestrutura e/ou prestação de serviço de transporte urbano e metropolitano (score 1,00).

\subsubsection{Tema: Transparência do processo de planejamento}

\section{a) Transparência e responsabilidade}

Por meio do site Portal da Transparência e do Diário Oficial da Prefeitura Municipal de Sinop (PMS) obteve-se a coleta das informações relativas a este indicador, no mês de dezembro de 2014. 
Para tanto, se avalia o resultado do score conforme tabela de critérios que variam da ausência de publicação formal e periódica sobre assuntos relacionados à infraestrutura, serviços, planos e projetos de transportes e mobilidade urbana (score 0,00), a existência de contratos e licitações para a execução de obras de infraestrutura e prestação de serviços de transportes público, estágio de desenvolvimento de planos e projetos, aplicação e fonte de recursos, e impactos sociais, econômicos e ambientais de planos e projetos de transportes e mobilidade urbana (score 1,00).

\subsubsection{Tema: Planejamento e controle do uso e ocupação do solo \\ a) Vazios urbanos}

Para a coleta de dados deste indicador foi utilizado um software de desenho assistido por computador e o arquivo mapa de uso do solo na cidade, fornecido por Sanches (2015), que pode ser observado na Figura 2.

Figura 2 - Uso do solo da área de abrangência da pesquisa

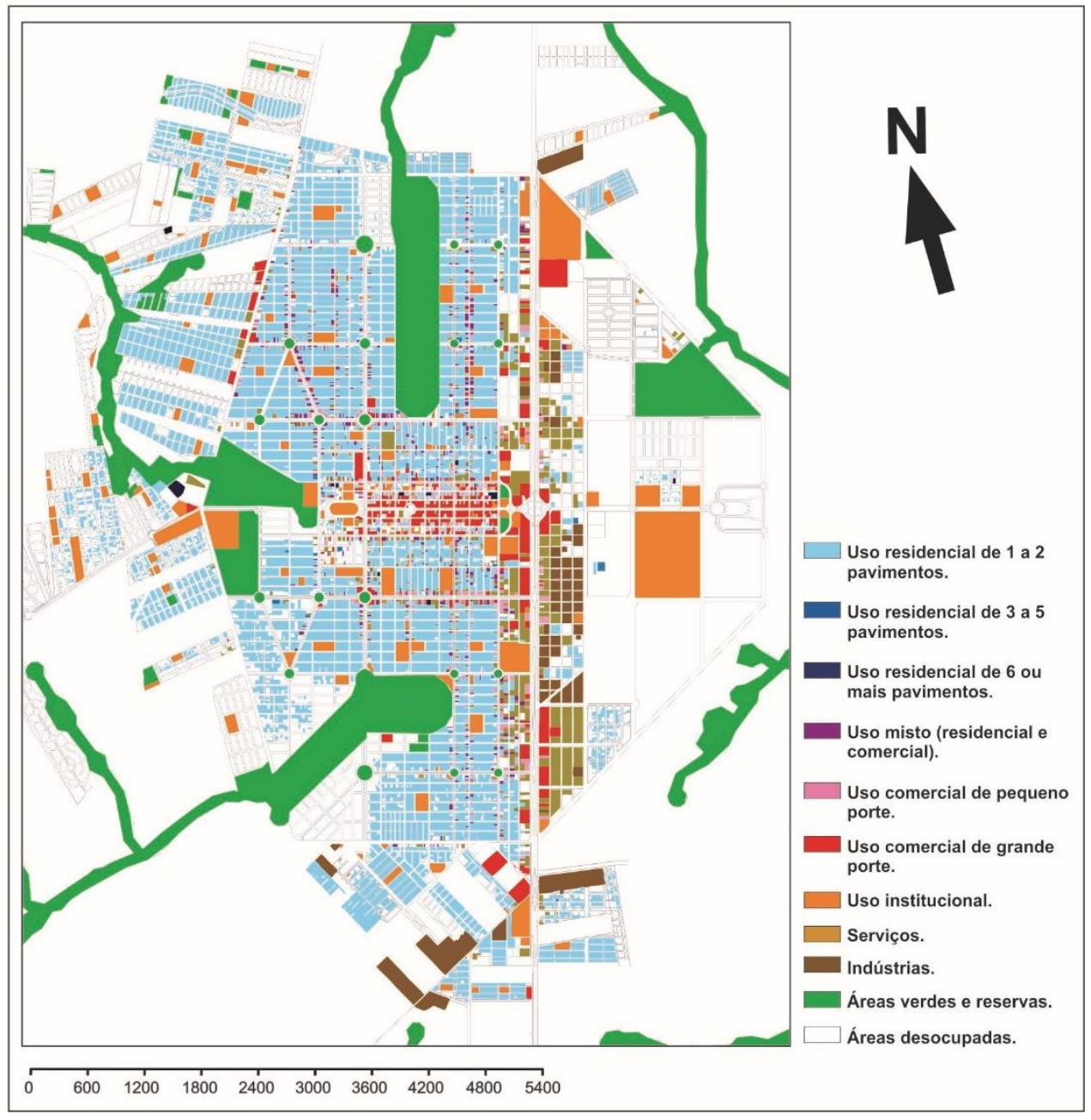

Fonte: Sanches, 2015

Assim, obteve-se a área de vazios urbanos, compreendendo todos os lotes e glebas já demarcados para loteamento e/ou que ainda não foram ocupados. Para tanto, desconsiderou-se os residenciais mais afastados como: Camping Clube, Alto da Glória, Jardim Planalto, Adalgisa, Aquarela Brasil, Residencial Carpe Diem, Residencial Portal da Mata, Residencial Mondrian e Residencial Ipanema. Trata-se de condomínios fechados ou loteamentos muito distantes do centro urbano (mais de $5 \mathrm{~km}$ de distância). Apesar de ainda estarem dentro do 
perímetro urbano atual (extremamente dilatado), não se conectam com a malha urbana do traçado urbano original e de suas adjacências.

A escala de avaliação faz referência à porcentagem da área urbana do município vazio ou desocupado, variando de $50 \%$ ou mais (score 0,00 ) a até $10 \%$ (score 1,00 ).

\section{b) Crescimento urbano}

Este indicador foi medido utilizando mapa de uso do solo do município, e por meio de software de desenho assistido por computador. Neste caso, foi realizado um buffer de $300 \mathrm{~m}$ nos novos loteamentos (ainda sem ocupação de residências), pelos quais irão passar os veículos de transportes de passageiros. No caso de Sinop, somente para vans, micro-ônibus e ônibus. Descarta-se um buffer de 500m para: metrôs, trens urbanos e bondes. Observa-se a razão entre a área total de novos projetos em áreas dotadas de infraestrutura de transportes e a área total de novos projetos em áreas sem infraestrutura de transportes, variando de 0,00 (score 0,00 ) a igual ou maior que 2 (score 1,00).

\section{c) Densidade populacional urbana}

Os dados para densidade populacional foram obtidos por meio do site do IBGE (IBGE, 2014), que aponta uma estimativa da população do município para o ano de referência, 2014. Também foi utilizado para os resultados o mapa da área efetivamente urbanizada do município,

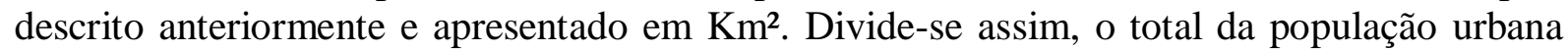
com o valor da área efetivamente urbanizada. Assim, a densidade populacional urbana pode variar de 5.000 habitantes $/ \mathrm{km}^{2}$ ou 50 habitantes/ha (score 0,00 ) a 45.000 habitantes $/ \mathrm{km}^{2}$ ou 450 habitantes/ha (score 1,00).

\section{d) Índice do uso misto}

Por meio de um software de desenho assistido por computador e com a ajuda do arquivo mapa de uso do solo, foi possível medir a área de uso misto da cidade. Esta área é toda área efetivamente urbanizada menos a área onde são considerados condomínios e loteamentos exclusivamente residenciais. Essa área medida é dividida pela área efetivamente urbanizada e deve ser representada em $\mathrm{Km}^{2}$. O resultado é extraído em porcentagem e, por meio de interpolação, obtém-se um score de acordo com a tabela de valores de referência fornecida pelo método.

Varia de quando a legislação urbanística municipal não permite o uso misto do solo, determinando zonas de usos exclusivos, resultando em intensa setorização da área urbana (score 0,00), até mais de $75 \%$ de área podendo ser de uso misto (score 1,00).

\section{e) Ocupações irregulares}

Os dados para este indicador foram coletados através de entrevista gravada com o presidente da Secretaria de Regularização Fundiária. Com a utilização de um software de desenho assistido por computador, foram medidas todas as áreas apontadas em $\mathrm{Km}^{2}$. Após, dividiu-se pela área efetivamente urbanizada e, por interpolação, o score foi obtido.

Assim, quando a área urbana constituída de ocupações irregulares e assentamentos informais corresponde a mais de $20 \%$ do total, o score é de 0,00 . No outro extremo, quando tal área corresponde a até $5 \%$ do total, o score é de 1,00.

\subsubsection{Tema: Planejamento estratégico integrado}

a) Planejamento urbano, ambiental e de transporte integrado

Este indicador ficou sem resultado devido à falta de dados confiáveis. Desta forma, o peso do score é redistribuído nos cálculos dos indicadores. Aqui seria avaliado se há cooperação 
formal entre órgãos gestores de transportes, meio ambiente e planejamento urbano no desenvolvimento de planos e programas de abrangência municipal.

\section{b) Efetivação e continuidade das ações}

O levantamento foi feito junto à Secretaria de Trânsito e Transporte Urbano (STU), por meio de entrevista concedida pela funcionária, que repassou as informações relacionadas ao indicador solicitado. O score foi obtido a partir da variação de constatação que nenhuma ação para transportes e mobilidade urbana prevista pela atual gestão foi efetivada (score 0,00), até que grande parte das ações para transportes e mobilidade urbana prevista pela atual gestão foi efetivada, tendo sido dada a continuidade às mesmas mesmo após mudanças no quadro da administração municipal.

\subsubsection{Tema: Planejamento da infraestrutura urbana e equipamentos urbanos \\ a) Parques e áreas verdes}

Para este indicador, foi medido o total de parques, praças e áreas verdes da cidade, onde a população tem acesso. Na realização destas medidas foi utilizado o mapa de uso solo da cidade (apresentado anteriormente), com a ajuda de um software de desenho assistido por computador. Para o resultado dividiu-se a área coletada pela população da cidade do ano de referência (2014). O score se deu por meio da variação que vai de igual ou inferior a $5 \mathrm{~m}^{2}$ por habitante, até igual ou superior a $25 \mathrm{~m}^{2}$ por habitante.

\section{b) Equipamentos urbanos (escola)}

Foi possível obter os dados para este indicador por meio de busca na internet a partir do site da Secretaria do Estado de Educação (SEDUC), onde se encontra o censo Escolar, que possibilitou a exploração de uma pesquisa realizada no ano de 2014 pela própria SEDUC. A partir do levantamento de todas as escolas infantis e de ensino fundamental, públicas e particulares, a avaliação do score se da após o uso da Equação 2.

$$
I=\left(\frac{\frac{E}{P}}{1000}\right)
$$

sendo:

$\mathrm{E}=$ significa o número de escolas contabilizadas; $\mathrm{e}$,

$\mathrm{P}=\mathrm{o}$ total da população estimada para o ano de 2014 .

O score foi obtido pelo número de escolas por 1000 habitantes, variando de igual ou inferior a 0,25 (score 0,00 ), até igual ou superior a 1,25 (score 1,00).

\section{c) Equipamentos urbanos (posto de saúde)}

A Secretaria Municipal de Saúde possui controle sobre os o número de postos de saúde. Assim, a partir de uma lista cedida pelo secretário de governo, foi calculado o indicador, a partir da Equação 3.

$$
I=\left(\frac{\frac{S}{P}}{100.000}\right)
$$

sendo:

$\mathrm{S}=$ número de equipamentos de saúde (postos de saúde) no município; e,

$\mathrm{P}=$ População total do município no ano de referência.

Obteve-se o score por meio do número de postos de saúde por 100.000 habitantes, podendo variar de até 10 (score 0,00 ) até 50 ou mais (score 1,00 ). 


\subsubsection{Tema: Plano Diretor e legislação urbanística}

\section{a) Plano Diretor}

O plano diretor do município de Sinop encontra-se disponível no site do Portal da Transparência (2015). Nesse critério foi avaliado se o município dispõe de Plano Diretor (score $0,00)$ até se o mesmo está atualizado há menos de 7 anos (score 1,00).

\section{b) Legislação urbanística}

As informações necessárias para este indicador encontram-se no site Portal da Transparência da PMS. O score é avaliado de acordo com os instrumentos que o município dispõe. Assim, varia desde quando o município não dispõe de legislação urbanística (score 0,00), até quando dispõe de Lei do perímetro urbano, Lei de zoneamento ou equivale, Lei de uso e ocupação do solo, Código de Obras, Código de Posturas, Legislação Sobre áreas de interesse especial, Legislação de interesse Social, Instrumentos para o Parcelamento, Edificação ou Utilização Compulsória, Outorga onerosa do Direito de Construir, Operações Urbanas Consorciadas ou outros instrumentos de planejamento urbano.

\section{c) Cumprimento da legislação urbanística}

Para obter informações deste indicador foi entrevistado um servidor público, que trabalha há mais de dez anos como fiscal de obras do município de Sinop. Por meio dessas entrevistas, foram levantadas as informações necessárias para a determinação do score, que é obtido de acordo com as atividades que a administração municipal realiza. Varia desde quando a administração municipal não tem realizado operações de fiscalização de obras e empreendimentos em desacordo com a legislação urbanística municipal (score 0,00), até quando realiza operações de fiscalização, notificação e autuação dos responsáveis, incluindo aplicação de sanções mais severas como paralisação das obras ou demolição parcial ou total dos empreendimentos (score 1,00).

\subsection{Forma de cálculo do IMUS setorial}

IMUS setorial indica o total de pontos obtido por cada domínio de forma que seja calculado pela Equação 4 abaixo e o valor obtido se dá conforme a soma dos produtos definidos pelos seguintes fatores, conforme Costa (2008): peso do tema relacionado ao indicador i (wi), peso do indicador i (wi) e o score do indicador (Xi).

$$
I M U S=\sum_{i=1}^{N} W i . W i . X i
$$

contudo, os pesos definidos pela dimensão social, econômica e ambiental estão relacionados aos pontos em que cada um deles seja condicionado na pontuação do tema. Para determinar o resultado das dimensões, deve-se realizar um cálculo onde se multiplicam os resultados dos temas pelas dimensões. Pressupõe que quando obtidos os valores agrupados dos temas e indicadores, se indica o desempenho do domínio calculado. Quando não se tem o resultado de alguns indicadores, os pesos são redistribuídos entre seus respectivos temas. O quadro abaixo demonstra os valores atribuídos aos pesos das dimensões, temas e indicadores definidos por Costa (2008). 
FERREIRA, PAULO; et al; Índice de Mobilidade Urbana Sustentável (IMUS) para o Domínio Planejamento Integrado em Sinop-MT. E\&S Engineering and Science, (2018), 7:2.

Quadro 1 - Pesos das dimensões, temas e indicadores

\begin{tabular}{|c|c|c|c|}
\hline \multicolumn{4}{|c|}{ Domínio: planejamento integrado. } \\
\hline Tema & Peso & Indicadores & Peso \\
\hline Capacitações de gestores. & \multirow{2}{*}{0,12} & Nível de formação de Técnicos e Gestores & 0,50 \\
\hline 0,37 & & Capacitação de técnicos e gestores & 0,50 \\
\hline Áreas centrais de interesse histórico. & \multirow{2}{*}{0,11} & \multirow{2}{*}{ Vitalidade do centro } & \multirow{2}{*}{1,00} \\
\hline 0,30 & & & \\
\hline Integraçâo regional & \multirow{2}{*}{0,12} & \multirow{2}{*}{ Consórcios intermunicips } & \multirow{2}{*}{1,00} \\
\hline 0,34 & & & \\
\hline Transparências do processo de planejamento. & \multirow{2}{*}{0,12} & \multirow{2}{*}{ Transparência e responsabilidade. } & \multirow{2}{*}{1,00} \\
\hline 0,32 & & & \\
\hline \multirow{5}{*}{ Planejamento econtrole do uso e ocupação do solo. } & \multirow{6}{*}{0,14} & Vazios urbanos & 0,20 \\
\hline & & Crescimento urbano. & 0,20 \\
\hline & & Densidade populacional urbana & 0,20 \\
\hline & & Índice do uso misto & 0,20 \\
\hline & & \multirow[t]{2}{*}{ Ocupações irregulares } & \multirow[t]{2}{*}{0,20} \\
\hline 0,32 & & & \\
\hline \multirow{2}{*}{ Planejamento Estratégico Integrado. } & \multirow{3}{*}{0,14} & $\begin{array}{c}\text { Planejamento urbano, ambiental e de transporte } \\
\text { integrado }\end{array}$ & 0,50 \\
\hline & & Efetivação e continuidade das ações & 0,50 \\
\hline 0,35 & & & \\
\hline \multirow{3}{*}{$\begin{array}{l}\text { Planejamentos da infraestrutura urbana e } \\
\text { equipamentos urbanos }\end{array}$} & \multirow{4}{*}{013} & Parques e áreas verdes & 0,33 \\
\hline & & Equipamentos urbanos (escola) & 0,33 \\
\hline & & Equipamentos urbanos (postos de saúde) & 0,33 \\
\hline 0,39 & & & \\
\hline \multirow{3}{*}{ Plano Diretor e legislação urbanística } & \multirow{4}{*}{0,12} & Plano Diretor & 0,33 \\
\hline & & Legilação urbanística & 0,33 \\
\hline & & Cumprimento da legislação urbanística & 0,33 \\
\hline 0,35 & & & \\
\hline Econômico & Peso & Indicadores de Desenvolvimento urbano & Peso \\
\hline
\end{tabular}

Fonte: Costa (2008)

\section{ANÁLISE DOS RESULTADOS E DISCUSSÕES}

\subsection{Resultados para o planejamento integrado}

\subsubsection{Tema: Capacitações de gestores}

a) Nível de formação de técnicos e gestores

O resultado para este indicador mostra que mais de $25 \%$ do quadro de funcionários tem formação superior, isto denota que as secretarias aqui mencionadas estão com técnicos e gestores qualificados. Contudo, mesmo que este seja um fator importante, percebe-se que a PMS ainda precisa aproveitar melhor seus profissionais. Verificou-se que muitos não estão exercendo a função relacionada à sua formação. De acordo com a metodologia, que não leva em consideração o desvio de função, o score foi 1,00, conferindo um caráter excelente neste quesito.

\section{b) Capacitação de técnicos e gestores}

Os cursos oferecidos às secretarias superam às quarenta horas anuais, conforme dados levantados. No entanto, estes dados foram coletados apenas verbalmente, o que indica um 
resultado não muito confiável. Porém, decidiu-se não descartar a entrevista. Obteve-se, portanto, um score de 1,00, excelente de acordo com o método.

\subsubsection{Tema: Áreas centrais de interesse histórico}

\section{a) Vitalidade do centro}

Aferiu-se o número de empregos no comércio da área central para o ano base 2010, tendo 821 comércios, 9174 domicílios e 7463 empregos. E, para o ano de referência 2014, 915 comércios, 11394 domicílios e 8081 empregos. Conforme cálculo pela equação 1, chegou-se a um valor de: 3,42 , acima de I > 1.50. Porém, deve-se ressaltar que o município tem enfrentado um esvaziamento da área central, com maior diversidade nas áreas afastadas. Observa-se, por exemplo, a construção de um shopping na área industrial e o aumento do número de comércios em regiões periféricas como Avenida André Maggi, e reestruturação da Av. Tarumãs. Percebese, neste caso, que as atividades noturnas têm sido deslocadas também neste sentido. O score para este indicador atingiu 1,00, excelente, já que a metodologia se atém aos termos da equação 1.

\subsubsection{Tema: Integração regional}

\section{a) Consórcios intermunicipais}

O município não participa de consórcio intermunicipal nesta área, conforme as leis que os regulamentam. Observa-se que não há interesse em buscar parcerias com municípios vizinhos para melhor aproveitamento do recurso público, através de consórcio regional, que poderia contribuir para uma melhor infraestrutura de transportes.

$\mathrm{Na}$ prática, estudantes universitários das cidades da região, por exemplo, ficam com poucas opções de deslocamento para Sinop no cotidiano, o que deveria motivar uma maior integração dos municípios. Desse modo, este indicador atingiu um score de 0,00 , sendo considerado péssimo.

\subsubsection{Tema: Transparências do processo de planejamento}

\section{a) Transparência e responsabilidade}

O município disponibiliza as informações necessárias exigidas pela transparência e responsabilidade, como: contratos e licitações, para execução de obras de infraestrutura e prestação de serviço de transporte público. Também é possível acompanhar o estágio de desenvolvimento de planos e projetos de transporte e mobilidade urbana, aplicação e fonte de recursos para planos e projetos de transportes e mobilidade urbana. Há ainda divulgação de impactos sociais, econômicos e ambientais e planos e projetos de transportes e mobilidade urbana. Contudo, observa-se que o acesso aos dados no site não é simplificado.

Já que a metodologia aplicada não leva em consideração a facilidade de acesso aos dados, tem-se um score de 1,00 , excelente.

\subsubsection{Tema: Planejamento e controle do uso e ocupação do solo}

\section{a) Vazios urbanos}

Obteve-se uma área de vazios correspondente a $8,76 \mathrm{Km}^{2}$, numa área efetivamente urbanizada de 51,92 $\mathrm{Km}^{2}$. Dividindo a área de vazios pela área efetivamente urbanizada, o resultado deste indicador atingiu valor de 16,83\%. Por interpolação através do processo de normalização, o score obtido é de 0,83 , ou muito bom. Contudo, a metodologia não leva em consideração o fato de muitos vazios se concentrarem próximos ao centro da cidade e regiões com boa oferta de infraestrutura. Também não considera o fato do perímetro urbano de Sinop ser dilatado, favorecendo a implantação de novos loteamentos distantes da malha existente. 


\section{b) Crescimento urbano}

A partir da aplicação de um buffer de 300m às áreas recentemente ocupadas, registrouse uma área de $5,39 \mathrm{Km}^{2}$. O resultado da divisão da área coberta pelo buffer com a área não coberta foi de $1,59 \mathrm{Km}^{2}$, definindo um valor de 3,40, de acordo com o método. Porém, deve-se ressaltar que o município cresce de forma desorganizada com loteamentos e condomínios muito afastados do centro urbano, e que grande parte da população depende do transporte público, causando muitos transtornos. Como a metodologia não leva em consideração esse último aspecto, o score é 1,00, excelente.

\section{c) Densidade populacional urbana}

A estimativa da população é de 126.817 habitantes, numa área efetivamente urbanizada de $51,92 \mathrm{Km}^{2}$. Dividindo a população pela a área efetivamente urbanizada, temos um valor de 2351,77 habitantes por $\mathrm{Km}^{2}$, ou seja, muito baixa. O resultado encontrado leva a um score de 0,00, péssimo de acordo com o método.

\section{d) índice do uso misto}

A área de uso misto da cidade, de acordo com o método, atingiu um valor de 47,75 $\mathrm{Km}^{2}$. Dividindo este valor pela área efetivamente urbanizada do município, que é de $51,92 \mathrm{Km}^{2}$, temse a área de uso misto correspondendo a aproximadamente $92 \%$. Consultando os valores de referência, por meio de interpolação, chega-se ao score igual a 1,00, que indica uma situação excelente em Sinop.

\section{e) Ocupações irregulares}

Em Sinop não foram identificadas moradias em áreas de risco, assim como não foram destacados terrenos sob domínio de posseiros. Já os loteamentos irregulares correspondem a uma área total de $1,66 \mathrm{Km}^{2}$. Como a área efetivamente urbanizada é de $51,92 \mathrm{Km}^{2}$, tem-se uma porcentagem é 3,20\%, chegando a um score de 1,00. Trata-se de uma situação excelente sob esse ponto de vista, oriundo da formação da cidade a partir de colonização privada e da grande oferta de terrenos.

\subsubsection{Tema: Planejamento estratégico integrado}

\section{a) Planejamento urbano, ambiental e de transporte integrado}

Devido à falta de dados confiáveis, optou-se em deixar sem cálculo este indicador. No entanto o seu peso foi redistribuído no respectivo tema e nos valores de referência.

\section{b) Efetivação e continuidade das ações}

O município não apresentou continuidade de programas de gestões anteriores. Sendo assim, o valor do score é de 0,00 , considerado péssimo.

\subsubsection{Tema: Planejamento da infraestrutura urbana e equipamentos urbanos}

a) Parques e áreas verdes

Aferiu-se um total de áreas verdes de $1.360 .530,60 \mathrm{~m}^{2}$.Assim, o cálculo do total de áreas medidas sobre o total da população, que é de 126.817 habitantes, chega ao valor de 10,71 $\mathrm{m}^{2} /$ habitantes. Por interpolação, o score obtido é de 0,29 .

Trata-se de um aspecto negativo da cidade, agravado pelo fato da falta de parques urbanos dotados de infraestrutura para esporte e lazer. As reservas verdes previstas no projeto original da cidade se mantêm, porém, sem manutenção e equipamentos adequados. 
FERREIRA, PAULO; et al; Índice de Mobilidade Urbana Sustentável (IMUS) para o Domínio Planejamento Integrado em Sinop-MT. E\&S Engineering and Science, (2018), 7:2.

\section{b) Equipamentos urbanos (escola)}

O município possui 19 escolas estaduais, 32 escolas municipais e 16 escolas privadas, num total de 67 escolas. Assim, a partir da estimativa da população do município de 126.817 pessoas, tem-se um total de 0,53 escolas/1000habitantes. Isso confere, após interpolação de dados, um score de 0,28 .

Trata-se de mais um aspecto negativo da avaliação realizada em Sinop. Observa-se falta de vagas em todos os níveis, em especial em creches e ensino infantil. Contribui para que estudantes e pais se desloquem por grandes distâncias para encontrar vagas em alguma unidade de ensino.

\section{c) Equipamentos urbanos (postos de saúde)}

A coleta dos dados para este indicador contabilizou vinte postos de saúde para uma população estimada de 126.817 habitantes. Por meio de interpolação, o score atinge valor de 0,13 . Novamente trata-se de um aspecto muito negativo, com atendimento precário e necessidade de longos deslocamentos dentro da cidade.

\subsubsection{Tema: Plano diretor e legislação urbanística}

a) Plano diretor

O plano diretor do município existe há mais de cinco anos, e é implantado mesmo havendo alguns códigos de lei desatualizados. Portanto, de acordo com os valores de referência, atinge um score de 0,50, razoável. Convém destacar que o ano de 2016 o Plano perdeu validade, não sendo registrada nenhuma iniciativa do poder público em atualizá-lo.

\section{b) Legislação urbanística}

A legislação urbanística não aplica todas as leis exigidas conforme foi elaborado. Portanto atinge um nível considerado baixo, com score de 0,60 .

\section{c) Cumprimento da legislação urbanística}

As informações sugerem que a secretaria PRODEURBS cumpre parcialmente as leis aplicadas em relação à fiscalização de obras, atingindo um score de 0,75 , com conceito bom.

\subsection{Análise do score dos domínios}

Assim, a partir da equação 4, obteve-se o IMUS de 0,551 para o planejamento integrado no município de Sinop. Considera-se que Sinop atingiu uma pontuação mediana de acordo com a escala proposta pelo método. Isso indica que há aspectos importantes a serem melhorados nesse município, dentre ele destacam-se a falta de consórcios intermunicipais, a baixa densidade populacional urbana, a falta de efetivação e continuidade das ações, a carência de parques e áreas verdes e de equipamentos urbanos como escolas e postos de saúde.

Apresenta-se a seguir, uma comparação do IMUS setorial com outras pesquisas publicadas por meio da aplicação desta ferramenta. 
Figura 3 - Comparação dos resultados obtidos para o IMUS.

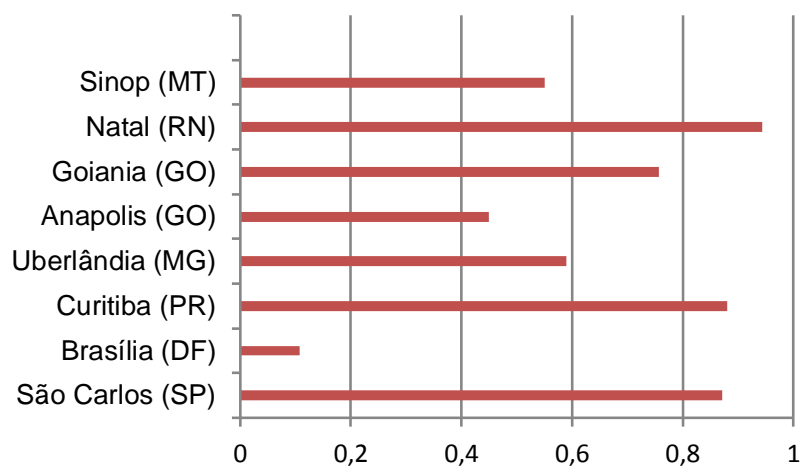

Fonte: Costa (2008), Pontes (2010), Miranda (2010), Assunção (2012), Morais (2012), Abdala (2013), Costa (2014) e Autoria Própria (2018).

Observa-se que Sinop se encontra numa posição análoga a de Anápolis e Uberlândia, também polos de importância regionais. Por outro lado, há ainda uma distância considerável de centros importantes e reconhecidos pela priorização da mobilidade sustentável, como é o caso de Natal, Curitiba e São Carlos.

\section{CONCLUSÃO}

O planejamento na gestão dos municípios é atualmente um desafio, que engloba diversos segmentos, de caráter econômico, social e ambiental. No entanto, é fundamental, pois visa corrigir distorções administrativas, de forma a facilitar a própria gestão. Nesse sentido, o IMUS demonstrou ser uma importante ferramenta para avaliar e monitorar o sistema de mobilidade urbana, desde que os dados possam ser obtidos com qualidade.

Aferiu-se, a partir do cálculo dos indicadores, que a gestão estratégica permeia à prática do planejamento no município de Sinop. Embora, ainda, incorporada de forma gradativa e precária. O município ainda apresenta carências significativas nesse quesito.

Observa-se que as ações de reconhecimento e fiscalização de obras estão presentes. Ainda assim, o município possui pendências, no que tange à aprovação de novos loteamentos em áreas remotas. Faltam escolas e postos de saúde e as ações, até o momento desenvolvidas, não acompanham o constante e acentuado crescimento da cidade.

Esses apontamentos refletem na baixa densidade observada por toda a cidade, mas, principalmente, em suas franjas. Não foram identificadas iniciativas no sentido de adensar as áreas com maior oferta de infraestrutura e de equipamentos urbanos. Apesar de presente no Plano Diretor Municipal, o IPTU progressivo no tempo, por exemplo, nunca foi aplicado. Novos loteamentos, de grandes dimensões, continuam a ser aprovados a grandes distâncias do centro comercial da cidade, já que o perímetro urbano local é bastante dilatado e há forte especulação imobiliária dos proprietários das terras.

Tais questões deveriam fazer parte de amplo debate com a sociedade sinopense. Contudo, no ano de 2016, o Plano Diretor vigente completou 10 anos de aprovação. Não se observou iniciativas no sentido de atualiza-lo, o que tende a agravar as questões levantadas neste trabalho, já que se trata de uma cidade em franco crescimento.

Destaca-se, por fim, que os problemas encontrados impactam de maneira mais significativas as populações mais carentes, que ocupam as áreas mais distantes do centro da cidade. Fica claro que não há uma justa distribuição dos ônus e bônus decorrente da urbanização, realidade da maioria das cidades brasileiras que se repete em Sinop. 
FERREIRA, PAULO; et al; Índice de Mobilidade Urbana Sustentável (IMUS) para o Domínio Planejamento Integrado em Sinop-MT. E\&S Engineering and Science, (2018), 7:2.

\section{REFERÊNCIAS}

ABDALA, I. M. D. R. Aplicação do Índice de Mobilidade Urbana Sustentável (IMUS) em Goiânia-Goiânia, GO. 2013. 203 p. Dissertação (Mestrado) - Pontifícia Universidade Católica de Goiás, Goiás-GO, 2013.

ASSUNÇÃO, M. A. D. Indicadores de mobilidade urbana sustentável para a cidade de Uberlândia, MG. 2012. 144 p. Dissertação (Mestrado) - Faculdade de Engenharia Civil, Universidade Federal de Uberlândia, Uberlândia-MG, 2012.

CARMO, Erika Motta; GARCIA NETO, Luiz da Rosa. Cadastro Territorial Multifinalitário e planejamento urbano, instrumento de domínio e poder. III Simpósio de Ciências Geodésicas e Tecnologias da Geoinformação, Recife, 2010

COSTA, L. P. Análise da mobilidade urbana de Natal/RN a partir do uso de indicadores de sustentabilidade. 2014. 173 p. Dissertação (Mestrado) - Universidade Federal do Rio Grande do Norte, Natal-RN, 2014.

COSTA, M. D. S. Um Índice de Mobilidade Urbana Sustentável. 2008. 248p.Tese (Doutorado). Escola de Engenharia de São Carlos, Universidade de São Paulo, 2008.

FERNANDES, M. Entraves do Planejamento Urbano no Brasil: dos planos de desenvolvimento integrado à fragmentação das políticas urbanas na RMSP. Tese (mestrado) - Faculdade de Arquitetura e Urbanismo da Universidade de São Paulo, 2013.

INSTITUTIO BRASILEIRO DE GEOGRAFIA E ESTATÍSTICA. População das cidades. Disponível em:

http:www.cidades.ibge.gov.br/xtras/perfil.php?lang=\&odmun=510790\&saerch=matoGrosso/sinop/inf ográficos:-informacoes-completas.- acesso em 21 agosto de 2015.

MAIA, L. C. A. Avaliação da qualidade do transporte público sob a ótica da mobilidade urbana sustentável - O caso de Fortaleza. Dissertação (Mestrado) - Escola de Engenharia de São Carlos, Universidade de São Paulo, São Carlos, 2013.

MANCINI, Marcelo Tadeu. Planejamento Urbano baseado em cenários de mobilidade sustentável. Dissertação (Mestrado) - Escola de Engenharia São Carlos da Universidade de São Paulo, São Carlos-SP, 2011.

MIRANDA, H. D. F. Mobilidade urbana sustentável e o caso de Curitiba. São Carlos, SP: 2010. 160 p. Dissertação (Mestrado) - Escola de Engenharia de São Carlos, Universidade de São Paulo, São Carlos-SP, 2010.

MORAIS, T. C. D. Avaliação e seleção de alternativas para promoção da mobilidade urbana sustentável - o caso de Anápolis, Goiás. 2012. 141p. Dissertação (Mestrado) - Escola de Engenharia de São Carlos, Universidade de São Paulo, São Carlos-SP, 2012.

PEREIRA, R.H.M. Tempo de deslocamento casa-trabalho no Brasil (1992 a 2009): Diferenças entre regiões metropolitanas, níveis de renda e sexo. Texto para discussão/Ipea. Brasília Rio de Janeiro: Ipea. 2013.

PONTES, T. F. Avaliação da mobilidade urbana na área metropolitana de Brasília. Brasília, DF: 2010. 250 p. Dissertação (Mestrado) - Faculdade de Arquitetura e Urbanismo, Universidade de Brasília, Brasília-DF, 2010.

PREFEITURA MUNICIPAL DE SINOP. Lei Complementar $n^{\circ} 29$ de 18 de dezembro de 2006. Institui o Plano Diretor de Desenvolvimento Integrado do Município de Sinop, Estado de Mato Grosso e dá outras providências. Sinop, 2006. 
FERREIRA, PAULO; et al; Índice de Mobilidade Urbana Sustentável (IMUS) para o Domínio Planejamento Integrado em Sinop-MT. E\&S Engineering and Science, (2018), 7:2.

SANCHES, M. C. J. Uma metodologia para a inserção do clima como critério para o planejamento urbano: análise da cidade de Sinop-MT. 2015. 232p.Tese (Doutorado), Universidade Federal do Rio de Janeiro, Rio de Janeiro, 2015. 